\title{
ASPECTOS EPIDEMIOLÓGICOS E IMUNITÅRIOS DA POLIOMIELITE EM CRIANÇAS MENORES DE UM ANO EM ÄREA DA REGIÃO DA GRANDE SÃO PAULO, BRASIL
}

\author{
Eliseu Alves Waldman* \\ Victório Barbosa* \\ Mitiko Fujita ** \\ Chang Chung Sing Waldman*** \\ José Paulo Gonzaga de Lacerda**
}

\begin{abstract}
WALDMAN, E. A. et al. Aspectos epidemiológicos e imunitários da poliomielite em crianças menores de um ano em área da região da Grande são Paulo, Brasil. Rev. Saúde públ., S. Paulo, 17:9-22, 1983.

RESUMO: Foram estudadas algumas características, de interesse epidemiológico, do comportamento da poliomielite na Região da Grande São Paulo, Brasil, salientando a importância da sua ocorrência em menores de um ano. Foram analisados os resultados de um inquérito sorológico, por provas de neutralização, em gestantes atendidas em Centros de Saúde de 16 Distritos Sanitários dessa Região. Com base nessas observações, foi dado destaque para determinadas condições que propiciam a infecção por poliovírus muito precoce, das crianças da área em estudo. Foi proposta a imunização, com a vacina Salk, das gestantes nos $5^{\circ}$ e $6^{\circ}$ meses de gravidez ou a imunização das crianças, com vacina oral trivalente tipo Sabin, em período anterior aos dois meses cie idade, ou seja, em torno do terceiro dia de vida, mas sem prejuízo da aplicação, em seguida, do esquema básico de imunização preconizada pelo Calendário de Vacinação oficial em vigor. Tais medidas visam à eliminação de possivel lacuna imunitária na faixa etária de menores de um ano.
\end{abstract}

UNITERMOS: Poliomielite. Inquéritos sorológicos. Imunização. Vigilância epidemiológica.

\section{INTRODUÇÃO}

O "Programa Nacional de Vacinação Contra a Poliomielite", iniciado em junho de 1980, do qual o Estado de São Paulo participou, alcançou, sem dúvida, alentadores resultados na Região da Grande São Paulo, ao permitir sensivel diminuição da incidência de casos dessa virose entre nós, comprovadá pela ocorrência de somente 4 casos em 1981 ; contrastando com a média anual de aproximadamente 122 casos no periodo de 1975 a 1980 (Tabela 1). Porém, como cautela e também para evitar conclusões precipitadas.

* Do Departamento de Epidemiologia da Faculd ade de Saúde Pública da USP - Ar. Dr. Amaldo, 715 - 01255 - São Paulo, SP, Brasil.

* Da Divisão de Biologia Médica do Instituto Adolfo Lutz - Av. Dr. Arnaldo, 355 - 01246 São Paulo, SP, Brasil.

** Da Secretaria de Estado da Saúde de São Paulo - Ar. Dr. Arnaldo. 351 - 01246 -- São Paulo, SP, Brasil. 
WALDMAN. E.A. et al. Aspectos epidemiológicos e imunitários da poliomielite em crianças menores de um ano em área da regiăo da Grande São Paulo, Brasil. Rev. Saúde públ., S. Paulo, $17: 9-22,1983$.

a partir de uma análise preliminar da situação, devemos lembrar 0 ocorrido em outras áreas do Mundo e justificado pelo conceito de $\operatorname{Cox}^{\theta}$ (1967) - enquanto 0 poliovírus não for eliminado, nenhuma população não confinada poderá ser considerada como protegida de exposição natural às cepas selvagens - traduzido, em termos práticos, pelo referido por Melnick e col. ${ }^{18}$ (1969) em relação ao reaparecimento dé casos de poliomielite em Houston, em 1968, após cinco anos de ausência.

Assim sendo, há necessidade de que, a partir de agora, sejam desenvolvidas análises mais elaboradas para o pleno êxito da vigilância epidemiológica da poliomielite que, daqui para frente, deverá preocupar-se em caracterizar resíduos de fontes de infecção e de suscetiveis. Com tal escopo, a análise de dados oficiais e de vários autores que têm estudado o assunto na Região da Grande São Paulo 2,3,20 permite verificar que a poliomielite ainda mantém as suas características de coença da primeira infância, com alta proporção de casos já no primeiro ano de vida, aspecto esse que não se viu alterado pela sensível diminuição de sua incidência, decorrente da implementação, especialmente nos últimos sete anos, do programa de imunização com vacina Tipo Sabin (Tabelas 1 e 2).

A Região da Grande São Paulo, em virtude de sua condição de área metropolitana e importante polo de atração populacional, com alta densidade demográfica, com algumas áreas apresentando maior concentração de habitaçōes precárias - cortiços e favelas principalmente - com uma insuficiente cobertura de saneamento básico $\mathrm{e}$ recebendo fluxo grande e regular de migrantes oriundos de outras Regiões do País 4,25 e da zona rural do próprio Estado, torna-se muito vulnerável à entrada constante de suscetiveis e de fontes de infecção, sobretudo de baixa idade. Esses fatores

T A B E L A 1

Morbidade por poliomielite e número de doses aplicadas de vacina tipo Sabin na Região da Grande São Paulo, durante o periodo d* 1970-1981.

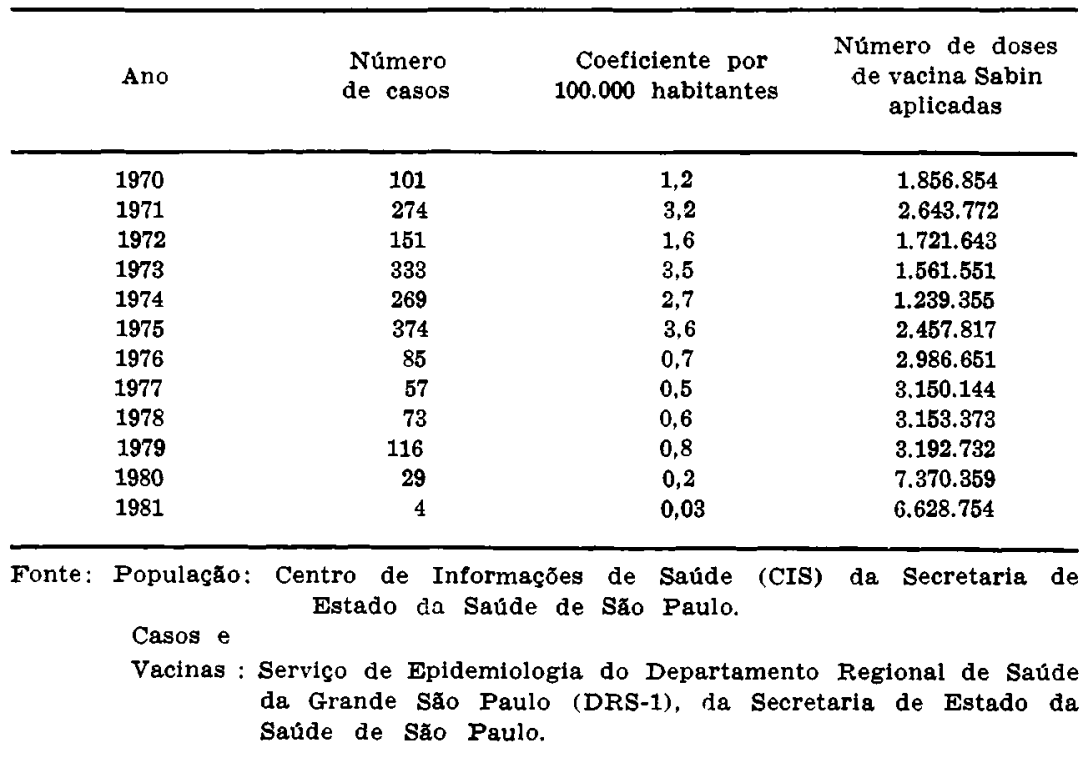




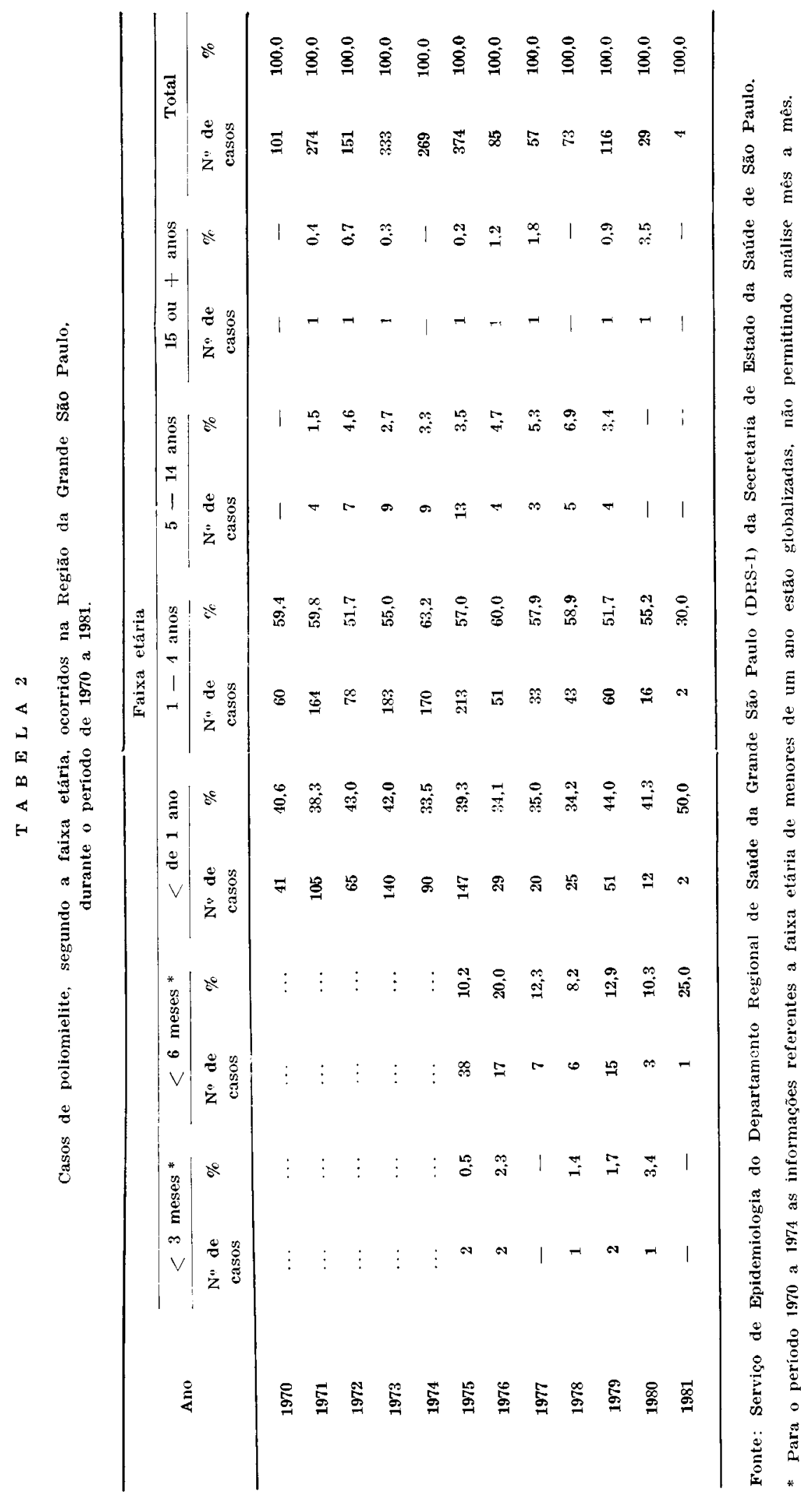


WALDMAN. E.A. et al. Aspectos epidemiológicos e imunitários da poliomielite em crianças menores de um ano em área da região da Grande São Paulo, Brasil. Rev. Saúde púbi., S. Paulo, $17: 9-22,1983$.

podem explicar 9 porquê da infecção pelo poliovirus se dar tão precocemente $2,10,20$.

Além dessas características, há outras que, se cotejadas com as anteriores, permitirão adequada compreensão do comportamento da poliomielite, na faixa etária de menores de um ans, na Região da Grande São Paulo. São elas: a) Ocorrência de infecção precoce por poliovirus em crianças - desde um até 35 dias de idade - conforme trabalhos de Carvalho ", Lacerda e col. ${ }^{15}$, Corradini e col.8 e Waldman e col. ${ }^{33}$. Esse último, realizado mais recentemente, 1980, pesquisando infecção intestinal por enterovirus em 300 recém-nascidos, encontrou $4,3 \%$ deles infectado pelo poliovirus com o predominio do tipo $1(92,3 \%)$, resultado esse que permitiu sugerir a possível ocorrência de formas menos freqüentes de tránsmissão - transplacentária e infecção no canal de parto - bem como a eventual participação da mãe como fonte de infecção. b) Verificação por Hutzler e col.12 (1980), em um grupo de recém-nascidos, de que $7,4 \%, 20,3 \%$ e $33,2 \%$ eram constituidos, respectivamente, por triplo, duplo e monossuscetiveis; e que $49,4 \%, 52,9 \%$ e $63,8 \%$ das crianças estudadas āpresentavam títulos de anticorpos neutralizantes inferiores a 16 , respectivamente para os sorotipos 1,2 e 3 de poliovirus. Além disso, Barbosa e Stewien ${ }^{3}$ já tinham mostrado, em 1975, a existência de lacuna imunitária nos menores de um ano, especialmente entre os 3 e $9 \%$ meses de vida, em análise de inquérito sorológico realizado no município de São Paulo. c) Segundo dados oficiais, durante o período de 1975 a $1981,1,0 \%$ e $11,8 \%$ do total de casos de poliomielite corresponderam, respectivamente, aos ocorridos em menores de 3 meses e de 6 meses (Tabela 3), o que salienta a importância que essa doença assume nas faixas etárias que precedem tanto o início (3\% mês) conı a conclusão (7ํ. mês) do esquema básico do Calendário de Vacinação oficial vigente. Assim é que os coeficientes anuais por 100.000 habitantes para essas faixas etárias, nesse periodo de tempo, calculados por nós, mostram que, de um lado, os relativos aos menores de 3 meses, nos anos de 1976, 1978, 1979 e 1980, superaram os da população geral e, de outro lado, que esses coeficientes nos menores de 6 meses são inferiores somente aos dos menores de um ano, com exceção dos de 1976, quando suplantou inclusive a taxa apresentada por esta última faixa etária.

Esses fatos, principalmente os relativos à ocorrência de infecção precoce e à existência de uma lacuna imunitária no primeiro ano de vida (itens a e b), revestem-se - a se considerar a atual situação de controle da poliomielite na Região em estudo - de capital importância para as nossas autoridades sanitárias no que diz respeito à vigilância epidemiológica da poliomielite, principalmente no sentido de uma ação, sempre oportuna e precoce, quanto à idade a se proteger pela vacina. Fica aqui consignado este importante e atual aspecto epidemiológico a ser considerado em sua vigilância, entre nós, o qual será, posteriormente, objeto de análise nos itens correspondentes.

A existência dessa lacuna, até agora, nos conhecimentos referentes ao comportamento da poliomielite em menores de um ano, levou à elaboração do presente trabalho que pretende ainda apresentar algumas propostas com vistas ao aperfeiçoamento das medidas, até aqui aplicadas, para manufenção do controle dessa doença, já em fase de vigilância epidemiológica, na Região da Grande São Paulo. Pará tanto, foi feito inquérito sorológico visando à determinação em gestantes dos niveis de imunidade para os três tipos de poliovírus.

\section{MATERIAL E METODOS}

Essa pesquisa foi levada a efeito em 393 gestantes, com a idade média de 24,5 anos e idades extremas variando de 15 a 46 anos, na Regiāo da Grande São Paulo, durante os meses de outubro a novembro de 1980 , periodo de tempo que se seguiu aos dois 


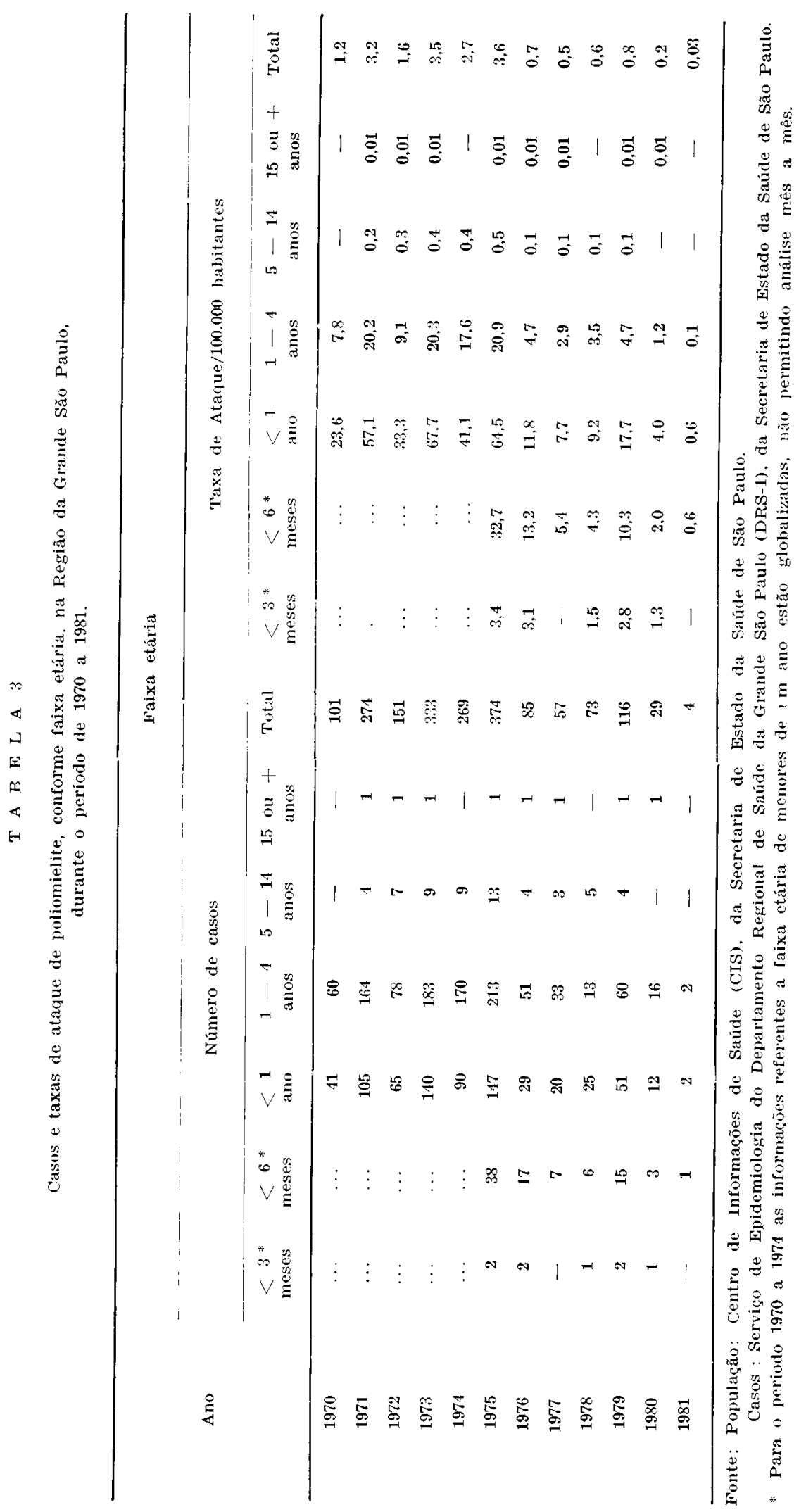


WALDMAN. E.A. et al. Aspectos epidemiológicos e imunitários da poliomielite em crianças menores de um ano em área da regiăo da Grande São Paulo, Brasil. Rev. Saúde públ., S. Paulo, $17: 9-22,1983$.

primeiros dias do "Programa Nacional de Vacinação contra a Poliomielite". Todas elas foram atendidas pelo Programa de Saúde Materna de 120 Centros de Saúde da Secretaria de Saúde do Estado de São Paulo, perfazendo, aproximadamente, $60,0 \%$ das unidades sanitárias existentes na época nessa Região.

Tais Centros de Saúde - de três tipos, segundo sua complexidade, programas a executar e atividades desenvolvidas - pertencem a 16 Distritos Sanitários da Grande São Paulo, constituídos cada qual por um determinado número de Centros de Saúde localizados nos Distritos e Subdistritos de $\mathrm{Paz}$ que compõem cada um desses Distritos Sanitários: Belenzinho, Butantã, Caieiras, Guarulhos, Itapecerica da Serra, Jabaquara, Mogi das Cruzes, Nossa Senhora do ó, Osasco, Penha de França, Santa Cecilia, Santo Amaro, São Miguel Paulista, Tucuruvi, Vila Maria e Vila Mariana (Figura); foram excluidos os Distritos Sanitários de
Vila Prudente, Lapa, Santo André, São Bernardo do Campo e São Caetano do Sul, em virtude de dificuldades operacionais em se obter e transportar as amostras de sangue de gestantes para os exames especificos.

As amostras de sangue foram colhidas por pessoal treinado e habilitado na coleta de amostras para exames de rotina dos Programas de Saúde da Secretaria; no caso em particular, do de Saúde Materna. Foram efetuadas nas próprias unidades sanitárias em que as gestantes eram atendidas ou, às vezes, em outras de maior complexidade, localizadas na mesma área, em virtude da não existência de colheita de material em todas elas. Essa colheita era realizada pela manhã e, nesse mesmo periodo, o sangue era remetido a um dos 4 Laboratórios Regionais do Instituto "Adolfo Lutz" (IAL) que participaram dessa pesquisa (Penha, Santa Cecilia, Osasco e Santo Amaro). Nesses laboratórios, a amostra era centrifugada à chegada, sendo o soro sobrena-

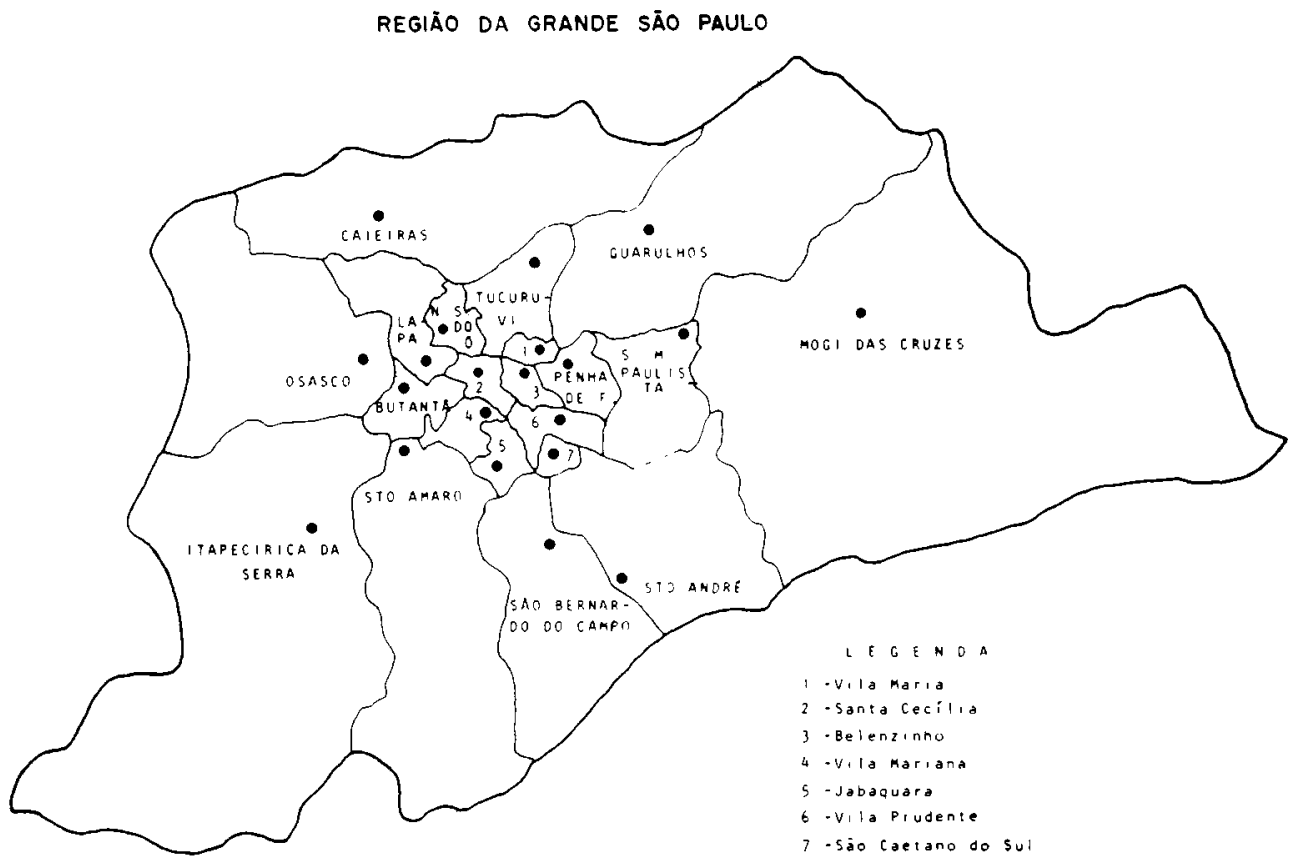


WALDMAN. E.A. et al. Aspectos epidemiológicos e imunitários da poliomielfte em crianças menores de um ano em área da região da Grande São Paulo, Brasil. Rev. Saúde públ., S. Paulo, $17: 9-22,1983$.

dante dividido em duas aliquotas, uma destinada aos exames sorológicos de rotina (previstos pelo Programa de Saúde Materna) e, outra, para os exames sorológicos especificos do presente inquérito. Esta última aliquota era enviada ao Serviço de Virologia do IAL, no qual imediatamente era armazenada em congelador a $-20^{\circ} \mathrm{C}$ até a data diu realização das provas de neutralização.

\section{Provas de neutralizaçāo}

As provas de neutralização foram realizadas segundo a microtécnica descrita por Rosenbaum e col.28. As estirpes de referência dos três tipos sorológicos foram os poliovírus 1 (Brunhilde), os poliovírus 2 (Lansing) e os poliovírus 3 (Leon).

Os soros foram diluídos de 1:8 a 1:512. A dose infectante para cada tipo de poliovírus cra de aproximadamente $100 \mathrm{TcD}{ }_{50}$. A mistura soro diluído mais vírus era incubada a $37^{\circ} \mathrm{C}$ por duas horas em câmara contendo $5 \%$ de $\mathrm{CO}_{2}$. A suspensão de células LLC-MK-2 era então adicionada, deixando-se as microplacas em câmara contendo $5 \%$ de $\mathrm{CO}_{2}$, durante aproximadamente $72 \mathrm{~h}$, à temperatura de $36^{\circ} \mathrm{C}$. Após esse periodo, efetuava-se a primeira leitura, ao microscópio invertido, sendo a segunda realizada $24 \mathrm{~h}$ após. Um efeito inibidor igual ou superior a $\mathbf{7 5 \%}$ do efeito citopático foi considerado como protetor, indicando a presença de anticorpos.

Para efeito de análise, consideramos como suscetiveis as gestantes com niveis séricos de anticorpos neutralizantes não detectáveis à diluição $1: 8$.

\section{RESULTADOS E DISCUSSAO}

A Tabela 4 permite-nos verificar que $84 \%$, $13,0 \%$ e $3,0 \%$ das gestantes são, respectivamente, triplo, duplo e mono-imunes, o que comprova a ampla disseminação das infecções causadas pelos três tipos de poliovirus na população estudada, o que era de se supor face ao que foi relatado anteriormente.

T A B E L A 4

Imuniciade para os três sorotipos de Poliovirus em gestantes atendidas em Centros de Saúde localizados em 16 Distritos Sanitários da Rezião da Grande São Paulo, Outubro e Novembro de 1980

\begin{tabular}{|c|c|c|c|c|c|c|c|c|c|}
\hline \multicolumn{2}{|c|}{ Triplo imunes } & \multicolumn{2}{|c|}{ Duplo imunes } & \multicolumn{2}{|c|}{ Mono imunes } & \multicolumn{2}{|c|}{ Triplo } & \multicolumn{2}{|c|}{ Total } \\
\hline No & $\%$ & No & $\%$ & Ne & $\%$ & No & $\%$ & No & $\%$ \\
\hline 330 & 84,0 & 51 & 13,0 & 12 & 3,0 & 0 & 0,0 & 393 & 100,0 \\
\hline
\end{tabular}

A proporção de imunes, segundo o sorotipo de poliovirus considerado, mostrou-se mais alta para o tipo 2, seguida, sucessivamente, pelos tipos 1 e 3 . Não foram detectados anticorpos neutralizantes para os sorotipos 1, 2 e 3 , respectivamente em 5,6\%, $4,8 \%$ e $8,9 \%$ das mulheres examinadas, sendo esta, portanto, a taxa de suscetiveis encontrada (Tabela 5). Esses resultados são semelhantes aos obtidos em população adulta de outras regiões do País, nas pesquisas realizadas por Niederman e col. ${ }^{22}$ e por Silva ${ }^{32}$, em recrutas e gestantes, respectivamente.

Conforme a Tabela 5, podemos notar ainda a alta proporção de níveis médios e baixos de títulos de anticorpos neutralizantes, concordando com referência efetuada 
WALDMAN. E.A. et al. Aspectos epidemiológicos e imunitários da poliomielite em crianças menores de um ano em área da região da Grande são Paulo, Brasil. Rev. Sańde públ., S. Paulo, $17: 9-22,1983$.

por Melnick e col.19, segundo a qual a ampla exposição à infecção aos poliovírus não determina, em população adulta, altos niveis séricos de títulos de anticorpos contra esses agentes.

Consoante os objetivos do presente trabalho, a discussão dos resultados levarão em conta o conhecimento já bem firmado de que os títulos de anticorpos neutralizantes contra os poliovirus das crianças ao nascer săo iguais ou ligeiramente inferiores aos das respectivas mães ${ }^{7,17}$.

Conforme vimos na introdução, reveste-se de alta importância entre nós, na fase atual de controle e vigilância epidemiológica da poliomielite, o conhecimento e a aplicação de medidas preventivas, o mais precocemente possivel, em relação a idade da população em que a mesma ocorre. Para que isso seja possivel é preciso entender quais os fatores determinantes da infecção, além dos anteriormente vistos, que a torna de ocorrência mui precoce.

Para atingirmos tal objetivo e alcançarmos melhor compreensão do problema a que nos propusemos estudar, quatro são as questões que se impōem: Quais as repercussōes na imunidade das crianças, no primeiro ano de vida, da alta proporçăo, de níveis médios e baixos de títulos de anticorpos neutralizantes em população de grávidas? Quais os fatores determinantes da infecçāo por poliovirus, em crianças menores de um ano, que podem ser alterados pelas campanhas de vacinação em massa? Quais as possiveis repercussōes, a médio e a longo prazo, nos niveis de imunidade da população para poliomielite, em face das campanhas de vacinação em massa? De que forma manter, por meis da vacinação de rotina, os niveis atuais de incidência da poliomielite na Região da Grande São Paulo, especialmente nas primeiras faixas etárias?

$O$ isolamento de poliovirus entre recém-nascidos da Região da Grande São Paulo 6,8,15,33 decorre da ampla dispersão desse agente, determinada pelas condições do ambien- te $3,10,20$ e, também, provavelmente, em função dos baixos níveis de títulos de anticorpos maternos apresentados por essas crianças, especialmente quando inferiores a 128, como ocorreu, em nossa amostra, em $79.9 \%, 68,2 \%$ e $89,9 \%$ dos casos, respectivamente para os tipos 1,2 e 3 de poliovirus (Tabela 5). Isto porque, nessas condições, segundo inumeros autores, existe a possibilidade de multiplicação desses vírus no trato intestinal dos néonatos 5,14,16,23,34. Essas acertivas são corroboradas pela ocorrência de alguns casos de poliomielite, na Região em estudo, nos primeiros dois meses de vida (Tabelas 2 e 3 ), propiciada, como já salientamos, por fatores ambientais e pela ausência ou esgotamento precoce dos anticorpos maternos, fato esse já referido por Cascio e Purpura 7 e Guaschino ${ }^{11}$, na Itália.

A ampliação da cobertura vacinal e especialmente as campanhas de vacinação em massa determinaram, como vimos anteriormente (Tabelas 1, 2 e 3), uma diminuição da incidência da poliomielite em todas as faixas etárias, em virtude do deslocamento do virus "selvagem" pelo vacinal 31 e, provavelmente, pela diminuição ou eliminação da lacuna imunitária nas crianças menores de um ano, verificada por Barbosa e Stewien ${ }^{3}$ e Hutzler e col.12, sem, contudo, alterar as condições ambientais que propiciam a infecção precoce pelos poliovirus.

Caso ocorra, realmente, uma menor circulação do poliovírus "selvagem", na Região da Grande São Paulo, em consequiência das campanhas de vacinação em massa, provavelmente verificaremos, a médio e Iongo prazo, niveis séricos de anticorpos neutralizantes, em adultos, mais baixos do que os observados em gestantes, na presente pesquisa, à semelhança do que ocorre em paises que já controlaram a poliomielite 19. Teremos, então, um maior número de crianças que apresentarão esgotados os anticorpos maternos em período anterior à época prevista para o início da imunização (3o mês), segundo o Calendário de Vacinação oficial, em vigor. Acresça-se, ainda, 
WALDMAN. E.A. et al. Aspectos epidemiológicos e imunitários da poliomielite em crianças menores de um ano em área da região da Grande São Paulo, Brasil. Rev. Saúde públ., S. Paulo, $17: 9-22,1983$.

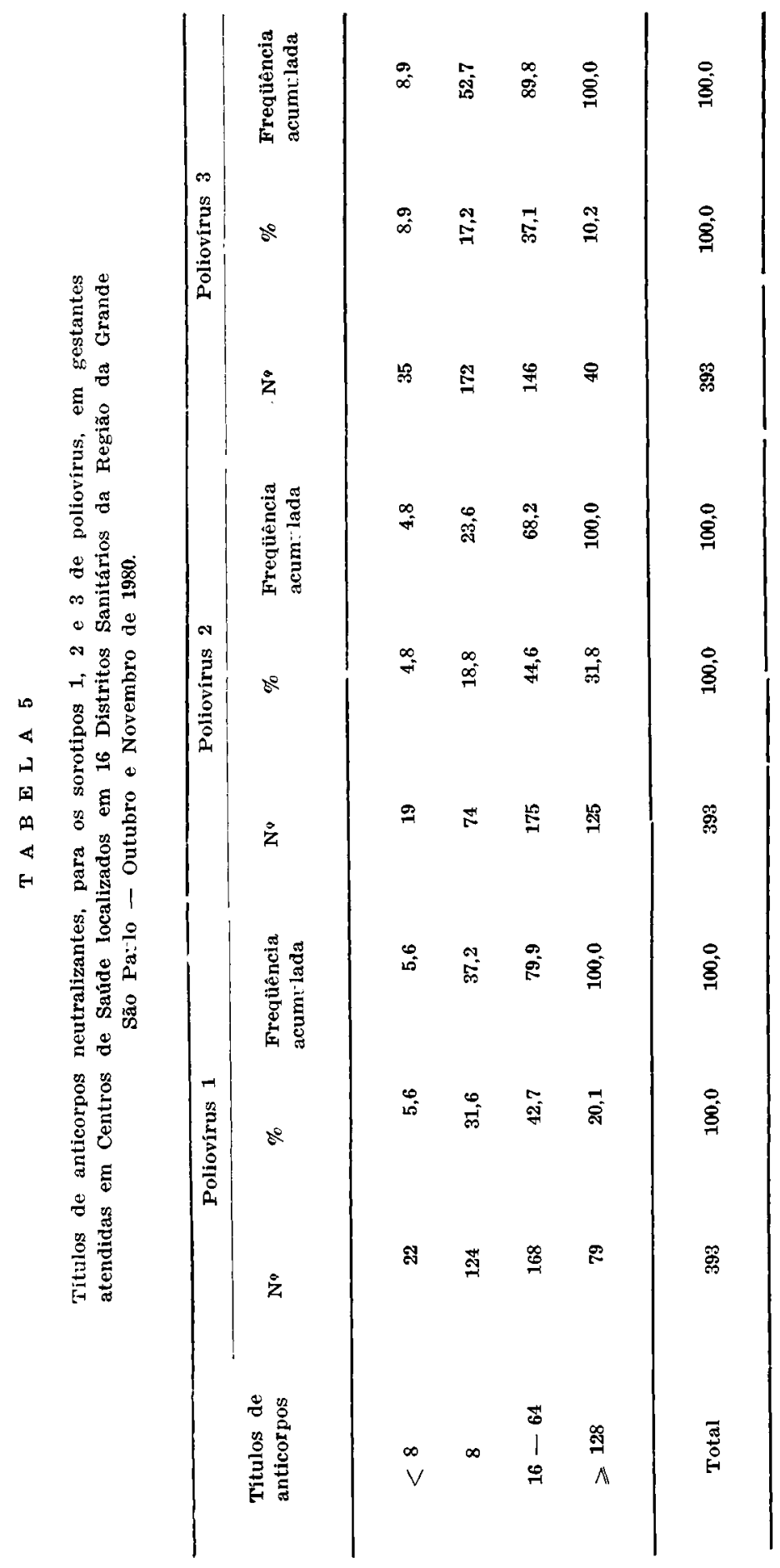


WALDMAN. E.A. et al. Aspectos epidemiológicos e imunitários da poliomielite em crianças menores de um ano em área da região da Grande São Paulo, Brasil. Rev. Saúde públ., S. Paulo, $17: 9-22,1983$.

um possivel aumento na freqüência de retardos no início do esquema básico de vacinação, caso venha a confirmar-se o esperado arrefecimento da vacinação de rotina, pela ênfase conferida às campanhas de vacinação em massa. Esses dois fatores favorecerão o provável reaparecimento ou mesmo ampliação da lacuna imunitária no primeiro ano de vida, assinalada por Barbosa e Stewien ${ }^{3}$ e por Hutzler e col.12, tornando possivel a ocorrência de surtos epidêmicos semelhantes ao descrito por Melnick e col.18, em Houston, em 1968.

Conforme o conceito de Martins da Silva e col. ${ }^{1 i}$ - a diminuição de anticorpos maternos ć uniforme, não variando com o tipo de poliovirus, e está em função dos níveis apresentados pela criança ao nascer - a citada lacuna imunitária, portanto, poderia ter seus efeitos atenuados, ao menos parcialmente, se os níveis de anticorpos an nascer fossem significativamente maiores que os encontrados em algumas pesquisas realizadas na Região da Grande São Paulo 12,21. Martins da Silva e col. ${ }^{17}$ relatam, por exemplo, crianças que apresentavam ao nascer niveis de títulos de 1.024 e permaneciam exibindo esses anticorpos maternos em quantias mensuráveis por 9 a 12 meses.

Portanto, ainda que inegáveis os excelentes resultados alcançados, na Região da Grande São Paulo, pelas campanhas de vacinação $\mathrm{cm}$ massa contra a poliomielite, iniciadas em 1980, consideramos oportuna a discussão de esquemas alternativos de vacinação de rotina que possam vir a substituir, a médio prazo, as vacinações em massa, garantindo, contudo, os niveis atuais de incidência dessa doença na região em questão. Com tal objetivo e levando em conta os dados apresentados e discutidos, consideramos conveniente o reestudo das sugestões já apresentadas, por alguns autores 1,11,17.20.21,29, que veremos a seguir, visando ao estabelecimento de imunidade contra a poliomielite, no primeiro semestre de vida.
Existem basicamente duas propostas. A primeira, defendida, entre outros, por Martins da Silva e col.17 e Guaschino ${ }^{11}$, refere-se à introdução da imunização com vacina tipo Salk em gestantes, como forma de aumentar precoce e significativamente a imunidade dos recém-nascidos e, assim, ampliar o período de proteção conferida. A outra, propugnada por diversos pesquisadores e especialmente voltada para os países "em desenvolvimento", nos quais a infecção pelo poliovírus já ocorre precocemente, consiste na introdução da vacinação com virus vivo atenuado em recém-nascidos, em torno do terceiro dia de vida, se possivel antes da alta do berçário $1,20,21,29$.

A primeira dessas proposições implica discussões e avaliações de ordem estritamente administrativas, já que não parece haver óbices de ordem técnica. A segunda, ro entanto, é, sem dúvida, polèmica, merecendo considerações mais aprofundadas dos pontos de vista administrativo e técnico. $O$ aspecto administrativo é a nosso ver, o menos problemático, uma vez que existem dados referentes ao final da década de 1960 sugerindo que aproximadamente $85 \%$ dos partos efetuados no municipio de São Paulo se fizeram em unidades hospitalares ${ }^{27}$, o que, operacionalmente, torna, até certo ponto, viável aquela proposta. No entanto, várias são as facetas, sob o ângulo técnico, que merecem minucioso estudo, antes de uma decisão, salientando-se entre as mais importantes, a interferência dos anticorpos maternos, da ingestão do leite materno e de líquido amniótico, a acentuada acidez gástrica logo após 0 nascimento e, finalmente, a ocorrência ou nāo de fenômeno de tolerância imunológica 29.

Muitos autores concordam que recém-nascidos com baixos niveis de anticorpos maternos apresentam boa resposta sorológica à vacinação $5,16,23,24$. Lepow e col.16 referem conversão sorológica em $83,0 \%$ dos recém-nascidos com títulos menores do que 128 , Campillo-Sainz e col.5 adotando níveis de títulos, as nascer, inferiores a 64 , apresen- 
WALDMAN. E.A. et al. Aspectos epidemiologicos e iminitários da poliomielite em crianças menores de um ano em área da região da Grande São Paulo, Brasil. Rev. Saúde públ., S. Paulo, $17: 9-22,1983$.

tam resultados semelhantes em $90 \%$ das crianças vacinadas e, finalmente, Pagano e col.23 mostraram que $80,0 \%$ dos recém-nascidos, que apresentavam titulos inferiores a 256, responderam adequadamente à vacinação.

$\Lambda$ interferência de anticorpos neutralizantes, existentes no leite materno, tem sua intensidade aumentada quando seus títulos sćricos são iguais ou superiores a 128; salienta-se, ainda, que Potkin e col. ${ }^{26}$, em cstudo realizado em Uganda, em 68 recém-nascido3, ao dosarem anticorpos neutralizantes no colostro e no sangue das crianças, nas $24 \mathrm{~h}$ que se seguiram ao nascimento, verificaram que em $67 \%$ dos casos, no colostro, os títulos apresentavam-se sensivelmente superiores aos do sangue, tendendo cles, entretanto, a se equipararem no terceiro dia. E de se ressaltar, por outro lado, que Katz e Plotkin ${ }^{13}$, apesar de concordarem com a interferência do leite materno na resposta imunitária do recém-nascido à vacina com vírus atenuado, anuem, entretanto, em deixar de considerar este fato, em determinadas condições, desde que fiquem asseguradas as vacinações subseqüentes.

A interferência da ingestão do líquido amniótico, em relação ao aspecto em questão, somente adquire importância na vigência de altos títulos de anticorpos circulantes na mãe; isto, porque sua concentração, nesse liquido, geralmente é muito inferior a do sangue, deixando, assim, de se constituir em óbice à vacinação de recém-nascidos no terceiro dia de vida 29 .

Em relação à acidez gástrica, admite-se que, mesmo alcançando um $\mathrm{pH}$ baixo nas primeiras $24 \mathrm{~h}$ após o parto, não parece influenciar a multiplicação do poliovírus vacinal no intestino, desde que a vacina seja administrada em altas doses 29.

Finalmente, não existem, ao que tudo indica, indicios de ocorrência do fenômeno de tolerância imunológica nas crianças vacinadas nos primeiros dias após o nascimento 30
Em vista do que foi exposto, parece-nos licito sugerir como rotina de um Programa de Saúde Materno-Infantil dos Centros de Saúde da Região da Grande São Paulo, a imunização com vacina tipo Salk nos $5^{\circ}$ e 6. meses de gestação e com vacina Sabin no $3 \circ$ dia de vida em recém-nascidos cujas mães não tivessem recebido a Salk, mantendo-se, em seguida, o esquema de imunização básica com a vacina oral Sabin aos 2,4 e 6 meses de vida. Esta medida poderá, em termos práticos e, sobretudo num programa de vigilância epidemiológica e controle da poliomielite, como é o caso da Região em tela, evitar que crianças no prımeiro semestre de vida se constituam em residuos de fontes de infeç̧ão e de suscetíveis e que gestantes, por sua vez, em residuos de suscetiveis. Esta medida constituirá, a médio prazo, um esquema alternativo de imunização, quando da suspensäo, pelas autoridades sanitárias, das campanhas de vacinação em massa contra a polıomielite.

\section{CONCLUSOES}

1. Ainda é mui precoce, na Região da Grande São Paulo, a ocorrência dos casos de poliomielite, sendo de grande magnitude no primeiro ano de vida, atingindo em proporção considerável, inclusive, as crianças menores de seis meses.

2. A distribuição etária dos casos de poliomielite, nessa Regiāo, não foi alterada pela implementação da imunização da população infantil com vacina tipo Sabin, ainda que, em decorrência dessa medida, tenhamos observado, nos últimos sete anos, uma significativa diminuição na incidência dessa doença.

3. Há, ao que tudo indica, na Região da Grande São Paulo, ampla proporção de níveis médios e baixos de títulos de anticorpos neutralizantes em gestantes, condicionando a alta vulnerabilidade das crianças à infecção por poliovírus, desde o seu nascimento até os dois meses de idade. 
WAIDMAN. E.A. et al. Aspectos epidemiológicos e imunitários da poliomielite em crianças menores de um ano em área da região da Grande São Paulo, Brasil. Rev. Saúde públ., S. Paulo, $17: 9-22,1983$.

4. Para o adequado, atual e oportuno desenvolvimento da vigilância epidemiológica da poliomielite, na Região da Grande São Paulo, objetivando a manutenção e o aperfeiçoamento do já conseguido controle dessa virose, torna-se necessária a implementação de medidas profiláticas convenientes que considerem, em especial, a existência de condições que propiciam a ocorrência, já nos primeiros meses de vida, de infecçôes por esses agentes.

5. Há, ao que parece, a necessidade de se indicar a imunização de gestantes, com a finalidade de sua proteção e, principalmente, para determinar a elevação dos anticorpos neutralizantes maternos que serão transmitidos, passiva e naturalmente, para os recém-nascidos, bem como, quando isso não for possivel, vacinar as crianças recém-nascidas, antes dos dois meses de idade e o mais precocemente possivel.

6. Recomenda-se a aplicação de vacina tipo Salk nos $5^{\circ}$ e $6^{\circ}$ meses de gravidez ou de vacina oral tipo Sabin nos recém-nascidos, em torno do 39 dia de vida, seguido do esquema básico de vacinação antipoliomielitica aos 2, 4 e 6 meses de vida. Esta medida deverá proporcionar, se aplicada na Região da Grande São Paulo, adequada imunidade às crianças menores de um ano, constituindo à médio prazo, um esquema alternativo de imunização, quando da suspensão, pelas nossas autoridades sanitárias, das campanhas de vacinação em massa contra a poliomielite.

\section{AGRADECIMENTOS}

As biólogas Ana Maria Solange do Val Ramos, Ruth Nogueira Cordeiro, Maria Alice Dias Pacheco, Christina Leopoldo e Silva e Maria do Carmo S. Tavares, do Instituto Adolfo Lutz, e à Dra. Maria Inês Baptistela, epidemiologista da Secretaria de Saúde do Estado de São Paulo, pela contribuição que prestaram à elaboração deste trabalho.

WALDMAN, E. A. et al [Some aspects of epidemiological relevance of the behavior of poliomyelitis in children of less than one year of age in an area of Greater S. Paulo, Brazil]. Rev. Satide públ., S. Paulo, 17:9-22, 1983.

ABSTRACT: Some characteristics of epidemiological relevance of the behavior of poliomyelitis in some Health Districts of Greater S. Paulo were studied, special emphasis being put on its occurrence in children of less than one year of age. Next, the results of serological investigation, performed by means of neutralization tests, on pregnant women attended by Health Centers in sixteen Health Districts of Greater $\mathbf{S}$. Paulo were analysed. Based on these observations the authors draw attention to certain conditions poliovirus infection in children. The immunization of pregnant women with Salk vaccine, during the fifth and sixth months of pregnancy, or, alternatively, the immunization of children with oral trivalent Sabin-type vaccine in the period before the age of two months, possibly about the third day after birth, is proposed; without, however, any change in the normal Iater application of the basic immunization project recommended by the official Vaccination Calendar. Such steps would aim at the elimination of conceivable immunity lacunas in children of less than one year of age.

UNITFRMS: Poliomyelitis. Serologic surveys. Immunization. Epidemiologic surveillance. 
WALDMAN. E.A. et al. Aspectos epidemiológicos e imunitários da poliomielite em crianças menores de um ano em área da região da Grande São Paulo, Brasil. Rev. Saúde públ., S. Paulo, $17: 9-22,1983$

REFERENCIAS

1. AMERICAN ACADEMY OF PEDIATRICS. Reports of the committee on infections diseases. 17th ed. Evanston, Ill., 1974.

2. BARBOSA, V. \& STEWIEN, K.E. Aspectos de importância para a vigilância epidemiológica da poliomielite na cidade de São Paulo, Brasil. Rev. Saúde públ., S. Paulo, 14:557-68, 1980.

3. BARBOSA, V. \& STEWIEN, K.E. Estado imunitário relativo a poliomielite das crianças de $0-12$ anos no municipio de São Paulo, Brasil e assistidas pelo Hospital Menino Jesis. Rev. Saude públ., S. Paulo, 9:137-53, 1975.

4. CAMARGO, C.P.F, et al. São Paulo 1975: crescimento e pobreza. São Paulo, Ed. Loyola, 1975.

5. CAMPILLO-SAINZ, C. et al. Immunization of newborn children with living oral trivalente poliovirus vaccine. $J$. Bact., 84:446-50, 1962.

6. CARVALHO, R.P. de S. Contribuição para o estudo dos enterovirus. Folia clin. biol., $35: 1-47,1966$.

7. CASCIO, G. \& PURPURA, R. Anticorpi antipolio in madri o in lattanti e malattia poliomielítica nei prime medi di vita. G. Mal. infett., 17:66, 1965.

8. CORRADINI, H.B. et al. Artrogripose múltipla congênita: apresentação de cinco casos. Rev. Hosp. Clin. S. Paulo, 34:28-33, 1979.

9. COX, H.R. Duration of in immunity following living poliovirus vaccine. In: International Conference on Vaccines against Viral and Rickttsial Diseases of Man, lst, Washington, D.C., 1966. Washington, D.C., Pan American Health Organization, 1967. p. 179-84 (PAHOScient. publ., 147).

10. Fox, J.P. et al. Studies on the development of natural immunity to poliomyelitis in Lousiana. I. Over-all plan methods and observation as to patterns of seroimm?nity in the study group. Amer, J. Hyg., 65:344-66, 1957.

11. GUASCHINO, S Per una protezione antipoliomielítica effetiva e precoce del lattante attraverso la vaccinoprofilassi in gravidanza. Min. med., 60:1461-4, 1969.

\section{BIBLIOGRAFICAS}

12. HUTZLER, R.V. et al. Niveis de anticorpos neutralizantes para poliovirus entre recém-nascidos em berçário de hospital localizado no município de São Paulo. [Apresentado no Congresso de Medicina Tropical, 18,, Ribeirăo Preto, 1982 mimeografado]

13. KATZ, M. \& PLOTKIN, S.A. Oral polio immunization of the newborn infant; a possible method for overcomming interference by ingested antibodies. $J$. Pediat., 73:267-70, 1968.

14. KRUGMAN, $\mathbf{S}$. et al. Immunization with livre attenuated poliovirus vaccine. Amer. J. Dis. Child., 101:23-9, 1961.

15. LACERDA, J.P.G. et al. Isolamento e identificação de poliovirus em São Paulo de 1967 a 1970. Rev. Inst. Adolfo Lutz, $31: 21-5,1971$.

16. LEPOW, M.I. et al. Effect of Sabin type 1 poliomyelitis vaccine administered by mouth to newborn infants. New Engl. J. Med,, 264:1071-8, 1961.

17. MARTINS DA SILVA, M. et al. Response of pregnant women and their infants to poliomyelitis vaccine. $J$. Amer. med. Ass., $168: 1-5,1958$.

18. MELNICK, J.L. et al. Developing gap in immunity to poliomyelitis in an urban areas. J. Amer. med. Ass., 209:1181-5, 1969.

19. MELNICK, J.L. et al, Environmental stlidies of endemic enteric virus infection. I. Community seroimmune patterns and poliovirus infection rates. Amer. J. Hyg., $65: 1-28,1957$.

20. NEVES, W.E. Alguns aspectos da poliomielite no primeiro semestre de vida: estudo de 241 casos. São Paulo, 1972. [Tese de Doutoramento - Faculdade de Medicina USP]

21. NEVES, W.E. et al. Vacinação antipoliomielítica, tipo Sabin, em crianças com um e três meses de idade. Rev. Inst. Med. trop. S. Paulo, 10:376-82, 1968 .

22. NIEDERMAN, J.C. et al. A nationwide serum sirvey of Brazilian military recruits, 1964. II. Antibody patterns with arboviruses, polioviruses, measles and mumps. Amer. J. Epidem., 86:319-29, 1967. 
WALDMAN. E.A. et al. Aspectos epidemiológicos e imunitários da poliomielite em crianças menores $\overline{d e}$ um ano em área da região da Grande São Paulo, Brasil. Rev. Saúde pübl., S. Paulo, $17: 9-22,1983$.

23. PAGANO, J.S. et al. The responses of premature infants to infection with attenuated poliovirus. Pediatrics, 29:794$-807,1962$.

24. PAGANO, J.S. et al. Variations in the responses of infants to living attenuated poliovirus vaccines. New Engt. J. Med., 264:155-63, 1961.

25. PIPPUS, A.M. \& CARLOS, J.A. A Grande São Paulo Hoje. SPAM, S. Paulo, 2:3-22, 1981.

26. PLOTIKIN, S.A. et al. Oral poliovirus vaccination in newborn African infants. Amer. J. Dis. Child., 111:27-30, 1966.

27. PUFFER, R.R. \& SERRANO, C.V. Caracteristicas de la mortalidad en la niñez. Washington, D.C. Organizacion Panamericana de la Salud, 1973. (OPAS-Publ. cient., 262)

28. ROSENBAUM, M.J. et al. A simplified method for vir: $s$ tissue culture procedures in microtitration plates. Proc. soc. exper. Biol. Med, 113:224-9, 1963.

29. SABIN, A.B. et al. Effect of oral poliovirus vaccine in newborn children. I. Excretion of virus after ingestion of large doses of type 1 or of mixture of all three types, in relation to level of placentally transmitted antibody. Pediatrics, 31:623-39, 1963.
30. SABIN, A.B. et al, Effect of oral poliovirus vaccine in newborn children. II. Intestinal resistence and antibody response at 6 months in children fed type 1 vaccine at birth. Pediatrics, 31:641-50, 1963.

31. SABIN, A.B. et al. Live orally given poliovirus vaccine, Effects of rapid mass immunization on population under conditions of massive enteric infection with other viruses. J. Amer, med. Ass., 173:1521-6, 1960.

32. SILVA, N.N. Imunidade natural à poliomielite em Porto Alegre, Brasil. Hospital, Rio de Janeiro, 58:109-18, 1960.

33. WALDMAN, E.A. et al. Ocorrência de infecção por poliovirus entre recém-nascidos internados em berçário de Hospital localizado no município de São PatioBrasil. [Apresentado no Congresso de Medicina Tropical, 18\%, Ribeirão Preto, 1982 - mimeografado].

34. WARREN, R.J. et al. The relationship of maternal antibody, breast feeding, age to the susceptibility of newborn infants to infection with attenuated polioviruses. Pediatrics, 34:4-13, 1964.

Recebido para publicaৎão em 30/07/1982

Aprovado para publicaçāo em 20/09/1982 